\title{
Imbalances in health workforce in a primary health centre (P.H.C.) of Darjeeling district, West Bengal, India
}

\author{
Nilanjana Ghosh ${ }^{1}$, Indranil Chakrabarti ${ }^{2}$, Manasi Chakraborty ${ }^{1}$ \\ ${ }^{1}$ (Department of Community Medicine, North Bengal Medical College, India) \\ ${ }_{2}^{2}$ (Department of Pathology, North Bengal Medical College, India)
}

\begin{abstract}
Health workforce includes clinically trained health professionals, health management and support workers. Imbalance in health workforce is a major challenge, as its size and quality positively determine country's ability to meet its goals of organizing and delivering health services, like immunization coverage, outreach of primary care etc. Unfortunately, India has uneven, inequitable and mal-distributed health workforce regarding number, skill, gender mix and type. The perceived gap being more in rural hilly areas, this study in a rural primary health centre (PHC) in Ghayabari, approximately 45 kilometres from Darjeeling was envisaged. The objectives of the study was to assess the status of health workforce in Ghayabari PHC in the hilly terrain of Darjeeling district and find out the associated reasons of any existing imbalance.A crosssectional study was conducted in Ghayabari PHC, from August to October 2011. Focus-Group-Discussion (FGD) with staff, local leaders, In-Depth-Interview (IDI) of medical officers, nurses and record review was done. There are two doctors, three nurses, ten beds for approx.16,800 population with 8.4 turnover rates. Indian Public Health Standard criteria are incompletely met regarding adequacy and health workforce distribution. 27.27\% posts are vacant, 13\% left jobs in last 3 yrs. Though emergency and referral services are present, outreach and home visits are irregular, increasing load on the PHC. FGD, IDI identify reasons as staff -shortages, absenteeism, attrition, less capacity building efforts, unskilled staff, intense communication problems in adverse terrain, harsh living and working conditions, absent job satisfaction, irregular supervision and no untied funds. Issues pertaining to staff shortage, skill imbalance and job satisfaction need to be addressed with concern and care to ensure primary health care at doorstep of community.
\end{abstract}

Keywords- primary health workforce imbalance, hilly terrains

\section{Introduction}

Human resources in health system are defined as "the stock of all individuals engaged in promotion, protection or improvement of population health".[1] Also referred to as health work-force, they cater to both private and public sectors apart from dealing with disease prevention, health promotion, public health interventions, research, management and support services. India has a dismal performance of key health indicators like maternal mortality, infant and child mortality, malnutrition, communicable diseases, tuberculosis, HIV etc. [1] These are attributed partly to lesser budget allocation for public health expenditure and also to inequitable distribution of health workforce. The Government of India is thus committed to raise public health expenditure from $0.9 \%$ of GDP to 2-3\% of GDP. [2] Public health expenditure in India had declined from 1.3\% of GDP in 1990 to $0.9 \%$ of GDP in 1999. State budgetary allocation is $5.5 \%$ whereas its contribution to public health expenditure is about $85 \%$. [2] Imbalance in health workforce again has been a challenging issue for the health planners and policy makers since its implications are grave. [3] It affects the quality and productivity of health services, round the clock availability of emergency facilities and utilization of trained individuals and satisfaction of staff as well as beneficiaries.There are various types of imbalances and they are measured by a variety of indicators. [4] From economic perspective, skill imbalance occurs when the employees could not provide the requisite skill needed by the employer, whereas from non- economic perspective, the normative ones, staff-shortage relative to defined norms is the main discrepancy. [5] Dynamic and static imbalances are another sub-category, in which the self- resolving ones are the dynamic imbalances. [3] Regarding typology of imbalances, there are five types: Profession/specialty imbalances deal with imbalances among various health professions and within a profession like shortage of particular type of specialists. Geographic imbalances refers to geographical mal-distribution of health workforce and disparities between urban-rural or poor-rich areas. Institutional/service imbalance and public/private imbalances also exist. Gender imbalances concerning differences in female/male representation in health workforce are also common. [3] The various measurement indicators as per World Health Organization (WHO) are employment indicators e.g. vacancies, growth of the workforce, occupational unemployment rate, activity indicators like overtime and normative population based indicators like doctor/population ratio, nurse/population ratio etc. [3] Whereas the advantages are they are easy to measure, widely used and universally applied in any health care system, the disadvantages are it excludes the private practitioners. Moreover the fund constraints tend to conceal the actual crisis. [3] In reality as there exists 
wide variations in type, skill, distribution and gender mix of health workforce and the health service delivery is largely inequitable and uneven. Reasons for such mal-distribution are unique geographical constraints like difficult terrains, migration of health personnel, lack of domestic training capacity, poor mix of skills, underutilization of trained staff, disparities in staffing pattern based on situation specific factors, ability to generate extra income, working conditions, job satisfaction, demographic imbalances and unsatisfactory salaries. [1] Size and quality of health work-force positively determine a country's ability to meet its goals of organizing and delivering health services, like immunization coverage, outreach of primary care, infant and child survival, maternal health among other outcomes. Thus, their job satisfaction and appropriate recruitment and retention strategies are mandatory to ensure better health for all, which is the ultimate goal of primary health care. WHO identified five key elements as namely universal coverage reforms, service delivery reforms, public policy reforms, leadership reforms and increasing stakeholder participation.[6] In India, comprehensive health care came with Bhore Committee in 1946, but concept of primary health care was formulated after 1978, with key to attaining Health for All by 2000. [7] India was a signatory to the Alma- Ata Conference in 1978, which emphasized the need of available, accessible, acceptable and affordable primary health care to reach allsections of society, including underserved and remote rural communities.A three- tier health system with primary health centres (P.H.C) in villages was established.It acted as first contact point of people with health care delivery system of the country was set up. [7] PHC caters to 30,000 population in urban areas and to 20,000 population in hilly, tribal and difficult areas. They are categorized into three categories, one without $24 \mathrm{X} 7$ services, second with 24 X 7 nursing facilities and third with 24 X 7 emergency hospital care facilities. [8] Standards being the main drivers for quality monitoring and improvement, the Indian Public Health Standards (IPHS) criteria regarding manpower, equipments, drugs and infrastructure are formulated separately for each. Essential services deal with the minimum assured services consisting of regular preventive, promotive and curative aspects and desirable services are those where the ideal level expected to be achieved are specified. [8] Manned by human resources in health, it acts as a referral centre for every four to six subcentres and in turn refers out cases to higher order public hospitals. Apart from outdoor, indoor, emergency services they implement existing and newly launched programs. It was stated that attaining Millenium Development Goals (MDGs) would be a far cry without adequate trained health workers. [9] Major bottlenecks in implementing health interventions for improving maternal and child health and addressing HIV/AIDS, malaria, tuberculosis are scarcity of adequately trained and motivated health workers. [10] Desired health output are not achieved because of absence of welleducated and properly managed health workers along with other constraints like thin infrastructure, drugsand supply systems, and information systems. [11] Number of cross-country ecological analysis have shown positive correlation between health workforce and health outcomes.[12 , 13] The World Health Report 2006 estimated that there is a dearth of approximately 4 million healthworkers for achieving minimum level of health outcomes. [9] Thus, health workers are integral to health care delivery system and play crucial role in health outcomes. Perceived gaps being more in remote difficult terrains, a study in rural hilly primary health centre (PHC) enduring harsh climaticconditions and rough geographical terrains was undertaken. Moreover, there is a dearth of published literature here on this issue. The objective of the study was to assess the status of health work-force in Ghayabari PHC, Darjeeling district and find out possible reasons for any existing imbalance.

\section{Materials and methods}

A cross- sectional study was carried out in Ghayabari P.H.C, Sukna Block, Darjeeling district of West Bengal, India for three months (August to October 2011). A rural hilly PHC located 45 kms. From the hill station of Darjeeling, it serves a population of approximately 16,800. Using multistage random sampling technique, Sukna Block was selected and subsequently from its three PHCs namely Sittong, Ghayabari and Bagora, Ghayabari PHC was selected for the study. After taking required permission from the Institutional ethics committee, Department of Community Medicine, North Bengal Medical College and Block Medical Officer of Health (BMOH) of Sukna Block, the Medical Officer in Charge (MOIC) of Ghayabari PHC was informed and explained about the importance of the study.The other doctors, nurses, paramedical staffs, frontline workers, clerical staffs were also explained and their consent to participate in the study was taken. All permanent and contractual staffsgiving willing consent were included. Staffs on maternity leave, or absent for more than three months were excluded from the study.Less common indicators like number of temporary/contractual staff, number of acceptable applicants per advertised vacancy and health outcomes were not in scope of study. Record Review was done to ascertain the status of imbalance and have an overview of working of the PHC. In- Depth -Interview (IDI) of BMOH, MOIC, other medical officers and nurses were carried out to determine reasons for imbalances, the difficulties faced by them despite their best efforts and ways to combat themenace. Focused- Group - Discussions (FGD)s with clerical, paramedical staffs, frontline workers were also conducted to know their perspective. A validated open-ended semi-structured schedule was also administered to find out the possible associated factors for the existing imbalance andits implications. 


\section{Results:}

Ghayabari PHC, located on hilly terrain serves approximately 16800 rural population. It caters to five subcentres. Rohini, the farthest subcentre, is around $10 \mathrm{kms}$ and Ghayabari subcentre is the nearest. The outreach sessions were conducted and the farthest is approximately $17 \mathrm{kms}$. Majority of the population resided Below Poverty Line, were Hindus and belonged to Nepali ethnicity.There were two residential medical officers, of whom one was a lady medical officer. MOIC was appointed by the State Government. There were three staff GNM nurses of whom two were residential. MOIC, three staff nurses, ANM and driver were permanent staff while the other staffs were contractual. There were 10 beds and the bed turnover rate was approximately 8.40. IPHS criteria were incompletely met regarding adequacy of infrastructure, drugs supplied, equipments and manpower. Approximately, 27.2\% posts were vacant indicating imbalance in health workforce adequacy and $13 \%$ left jobs in last three years. Vacant posts were not filled up very regularly after their retirement or resignation. Local people were maximally self-employed. Led by MOIC, the other existing staffs were another medical officer, three staff nurses, one male health assistant, one female auxiliary nurse midwife (ANM), two pharmacists, one lab-technician, one driver and eight Group IV staffs making a total of nineteen staffs. In addition to the IPHS criteria, five staffs were also helping in the activities of PHC. Six staffs were permanent while the rest were contractual. AYUSH practitioners, account manager, health assistant female, Ophthalmic Assistant, Data handlers, clerks, community-based rehabilitation worker were not present. With respect to health workforce distribution, among the essential seventeen people required for efficient running of PHC, five were deficit and of total desired twenty five people, ten were deficit indicating mal- distribution.

\begin{tabular}{|c|c|c|c|}
\hline STAFF & Essential (17) & Desirable (25) & Chayabari (19) \\
\hline Medical Officer & 2 & 2 & 2 \\
\hline $\begin{array}{l}\text { AYUSH } \\
\text { Practitioner }\end{array}$ & - & 1 & - \\
\hline $\begin{array}{l}\text { Account } \\
\text { Manager }\end{array}$ & - & 1 & - \\
\hline Pharmacist & 1 & 2 & 2 \\
\hline Nurse (Staff) & 1 & 5 & 3 \\
\hline $\begin{array}{l}\text { Health } \\
\text { Worker(F) }\end{array}$ & 1 & 1 & 1 \\
\hline Health Ast.(M) & 1 & 1 & 1 \\
\hline $\begin{array}{l}\text { Health Asstt.(F) } \\
\text { OphthalmicAstt. } \\
\text { Comm.Based } \\
\text { Rehab.Worker } \\
\text { Clerk } \\
\text { Data Handler } \\
\text { Lab.Tech. } \\
\text { Driver } \\
\text { Cold chain } \\
\text { Astt./ClassIV } \\
\text { Class IV }\end{array}$ & $\begin{array}{l}1 \\
1 \\
- \\
2 \\
1 \\
1 \\
1 \\
- \\
4\end{array}$ & $\begin{array}{l}2 \\
- \\
1 \\
2 \\
- \\
2 \\
\text { Optional } \\
1 \\
4\end{array}$ & $\begin{array}{l}- \\
- \\
- \\
- \\
- \\
1 \\
1 \\
1 \\
7\end{array}$ \\
\hline
\end{tabular}

The above table depicts the health workforce in Ghayabari PHC in comparison to essential and desired criteria of IPHS as per the revised guidelines 2010 .

Training programs like SBA training, ligation Camps, NVBDCP trainings were received mostly by doctors, though nurses received few like IDSP. Due to acute staff crisis and additional load of paper works in absence of data handlers, there was overburdening of the staffs .Outreach, home visits, immunization services were carried out despite the odds.Around forty-five patients per day attended outdoor, the numbers increased in summer and decreased in winters. Emergency facilities, regular drug supply to patients including DOTS therapy, normal delivery facilities, diagnostic facilities of malaria and tuberculosis, implementation of national programs and referral services were run .Generally PHCs are run under Minimum Need Programme, but it was a non- sanctioned PHC and thus receives less untied funds.

Record review confirmed the existing imbalance in health workforce. Staff shortages, absenteeism, attrition, absent during stipulated duty hours, unauthorized leaves and lack of competent skilled staff compounded the problem. FGD, IDI and questionnaire method identified few possible reasons as rough difficult rough terrains, harsh climatic conditions, subsequently adverse living and working conditions, insufficient capacity building efforts, low motivation, no job satisfaction and inadequate personnel to population ratio jeopardizing work. Inadequate infrastructural and complementary facility support led to under-utilization of trained staff and lack of need based planning to achieve service targets affected motivation, enthusiasm and efficiency of staff. Water crisis, electricity shortages, bad broken roads due to landslides causing intense communication problems, linguistic barrier for non-local staffs, increased daily costs , inadequate residential facilities, lack of regular comforts caused widespread discontent and dis-satisfaction and reduced job satisfaction. Mismatch between thin infrastructural support and man-power caused wasteful expenditure of 
already scarce resources. They opined that better living conditions, improving career prospects,more availability of diagnostic facilities, pay - hikes, planning and implementing policies relevant to situation specific factors and more supervision and monitoring could help the issue.

\section{Discussion}

Remote difficult terrains and underserved areas lack the adequate number of trained health workers due to geographical disadvantages. "Under-served areas" refer to areas where access to qualified healthworkforce is limited and comparatively poorer populations reside. [9] Insufficient capacity building efforts and inability to retain workers in required places have led many countries to report acute staff crisis. Serving approximately one half of rural global population are only $38 \%$ of total nursing workforce and less than $25 \%$ of total physicians. [9] In Cote d'Ivoire, Mali, Democratic Republic of Congo, health workers are produced in excess causing maldistribution, with crisis in rural areas and medical un-employment in urban sectors. [9] Most commonly extent of mal-distribution is displayed using health worker's densities in urban compared with rural areas. Others include vacancy rates, turn-over rates, attrition rates, absenteeism, and unemployment rates. In Bangladesh, $30 \%$ of nurses are located in four metropolitan districts where only $15 \%$ of population lives. [12] In South Africa, $46 \%$ live in rural areas, but only $12 \%$ of doctors and $19 \%$ of nurses work there. Rensburg further stated that only $27 \%$ of general practitioners, $25 \%$ medical specialists, $7 \%$ dentists and $6 \%$ psychologists practice there. [9] In Kenya, $64 \%$ of psychiatrists are working in Nairobi, which accounts for only $7.5 \%$ of population. [9] In Mali in 2002,265 midwives were posted in regional hospitals, 164 at the peripheral level, thus only $24 \%$ deliveries were attended by skilled professional. In USA, serving $20 \%$ rural population are $9 \%$ registered physician. [14] In France, large disparities exists in density of general practitioners, with more clustering around well-off areas of south of France and Paris. [15] In 2006, rural Canada covering $99.8 \%$ of territory, accounted for $24 \%$ of population and $9.3 \%$ of physician's worked there. But unfortunately, rural area crisis in developed countries, pulls healthworkforce from developing countries, creating adverse consequences for the latter. [9] In Tanzania, in 2003, 60\% posts for nursing personnel were vacant. The NHS in England reported 'three month' vacancies.

However, funded but unfilled posts that are recorded vacant give indications of 'hard to fill' jobs. It is observed that recent trends of health workforce are to move towards work-life balance models, get motivated by non-financial rewards and tendency to switch jobs if discontent. Unfit recruitment and retention strategies lead to staff- shortages, whereas lack of job-satisfaction and motivation of health workers lower quality and productivity. Factors influencing choices of location in rural and remote areas known as 'push' and 'pull' factors.[12,16] "Pull" factors attract individuals to new destinations like improved employment opportunities, career prospects, higher income, better living conditions and more stimulating environment. 'Push' factors repel individuals from locations like loss of employment opportunity, low wages, poor living conditions, harsh terrains, and lack of schooling for children.[17] Various theories and models exist trying to explain factors concerning workers' mobility. Economic theory like Neoclassic Wage Theory, suggests that financial motives and scope of employment are the main driving force. [17] Behavioral theories, like Maslow and Herzberg holds job satisfaction of workers as crucial deciding factor. [9]

To identify factors involving locations, various methods used are traditional semi-structured interviews, focus group discussions and some recent methods as discrete choice experiments. [18] Moreover health system strengthening aimed to improve accessibility, sustainability, utilization and quality of health delivery system by reinforcing the human resources in health is fast emerging. [19] Thus a competent, responsive and productive health workforce, evenly and equitably distributed is mandatory to ensure primary health care at door step of the community.

Availability of health workforce in remote adverse terrains are dependent on the policies and interventions that influence their decision to stay or leave those areas and responsiveness of the health system to them. [19] Appropriate recruitment and retention strategies, sound policy support, liberal fund allocation, staff motivation, creating job satisfaction, better infrastructural supportand efficient supervision and monitoring could reduce health workforce imbalances. [9]

To deliver available, accessible, affordable, equitable integrated preventive promotive and curative health services, the health workforce needs to be adequately trained, motivated and adequate. A larger study on this important issue is recommended.

\section{References}

[1]. WHO. Not Enough Here... Too Many There...Health Workforce in India.World Health Organization .Country Office for India 2007. pp. 1. Available at: http://www.whoindia.org/LinkFiles/Human Resources Health Workforce in India-Apr07.pdf

[2]. National Rural Health Mission (2005-2012). Mission Document. Available at: http://mohfw.nic.in/NRHM/Documents/MissionDocument.pdf.

[3]. Zurn P, Poz M D, Stilwell B ,Adams O. Imbalances in the health workforce. Briefing paper. World Health Organization. Evidence and Information for Policy. Health Service Provision 2002. pp. 7-42. Available at: http://www.who.int/hrh/documents/en/imbalancesbriefing.pdf.

[4]. Cohen M. Labor shortages as America approaches the twenty-first century. The University of Michigan Press. Ann Arbour 1998. 
[5]. Feldstein P. Health care economics, Fifth Edition, Delmar Publishers, New-York, 1999.

[6]. WHO. Primary health care .WHO Document 2011. Available at:http://www.who.int/topics/primaryhealthcare/en.

[7]. Park K. Park's textbook of preventive and social medicine. In:Park K (ed). Health care of the community.21 ${ }^{\text {st }}$. Edition. M/s BanarasidasBhanot publishers. Jabalpur 2011.pp. 828.

[8]. Indian Public Health Standards (IPHS) For Primary Health Centers Guidelines (Revised 2010). Directorate General of Health Services Ministry of Health \& Family Welfare.Government of India.pp.3-6. Available at: http://www.mohfw.nic.in/NRHM/IPHSRevisedDraft/PHCRevisedDraft.pdf.

[9]. WHO. Increasing access to health workers in remote and rural areas through improved retention. Background paper for the first expert meeting to develop evidence-based recommendations to increase access to health workers in remote and rural areas through improved retention. Geneva 2009. pp.4-18. Available at : http://www.who.int/hrh/migration/backgroundpaper.pdf

[10]. Dreesch N, Dolea C, Poz MRD, Goubarev A, Adams O, Aregawi M, et al. An approach to estimating human resource requirements to achieve the Millennium Development Goals. Health Policy and Planning 2005; 20(5): 267-76.

[11]. Travis P, Bennett S, Haines A, Pang T, Bhutta Z, Hyder AA, et al. Overcoming health-systems constraints to achieve the Millennium Development Goals. The Lancet 2004; 364: 900-06.

[12]. Zurn P, Poz MRD, Stilwell B, Adams O. Imbalance in the health workforce. Human Resources for Health $2004 ; 2: 13$.

[13]. Anand S, Bärnighausen T. Human resources and health outcomes: cross-country econometric study. The Lancet 2004; 364: 1603-9

[14]. Hamilton K, Yau J. The Global Tug-of-War for Health Care Workers. Migration Policy Institute, Washington DC 2011. Available at: http://www.migrationinformation.org/Feature/print.cfm?ID=271

[15]. Cash R, et Ulmann P. 2008, Projet OCDE sur la Migration des Professionnels de Santé : Le Cas de la France. OECD Health Working Papers 36.

[16]. Dieleman M, Harnmeijer JW. Improving health worker performance: in search of promising practices. WHO Geneva 2006. Available at http://www.who.int/hrh/resources/improving_hw_performance.pdf.

[17]. Lehmann U, Dieleman M, Martineau T. Staffing remote rural areas in middle and low income countries: A literature review of attraction and retention. BMC Health Services Research 2008; 8(19):1-10.

[18]. Chomitz KM et al, 1998. What do doctors want? Developing incentives for doctors to serve in Indonesia's rural and remote areas. The World Bank Policy Research Working Paper 1888. Available at: http://www.worldbank.org/html/dec/Publications/Workpapers/WPS1800series/wps1888/wps1888.pdf.

[19]. Alva S , Kleinau E, Pomeroy A, Rowan K .Measuring the Impact of Health Systems Strengthening . A Review of the Literature . U.S. Agency for International Development 2009. pp. $7-15 . \quad$ Available at: http://www.usaid.gov/ourwork/globalhealth/hs/publications/index.html. 